\title{
Health conditions and residential concentration of poverty: a study in Rio de Janeiro, Brazil
}

Célia L Szwarcwald, Francisco Inácio Bastos, Christovam Barcellos, Maria de Fátima Pina, Maria Angela Pires Esteves

\begin{abstract}
Study objectives-To establish the geographical relation of health conditions to socioeconomic status in the city of Rio de Janeiro, Brazil.

Design-All reported deaths in the municipality of Rio de Janeiro, from 1987 to 1995, obtained from the Mortality Information System, were considered in the study. The 24 "administrative regions" that compose the city were used as the geographical units. A geographical information system (GIS) was used to link mortality data and population census data, and allowed the authors to establish the geographical pattern of the health indicators considered in this study: "infant mortality rate"; "standardised mortality rate"; "life expectancy" and "homicide rate". Information on location of low income communities (slums) was also provided by the GIS. A varimax rotation principal component analysis combined information on socioeconomic conditions and provided a two dimension basis to assess contextual variation.

Main results-The 24 administrative regions were aggregated into three different clusters, identified as relevant to reflect the socioeconomic variation. Almost all health indicator thematic maps showed the same socioeconomic stratification pattern. The worst health situation was found in the cluster composed of the harbour area and northern vicinity, precisely in the sector where the highest concentration of slum residents are present. This sector of the city exhibited an extremely high homicide rate and a seven year lower life expectancy than the remainder of the city. The sector that concentrates affluence, composed of the geographical units located along the coast, showed the best health situation. Intermediate health conditions were found in the west area, which also has poor living standards but low concentration of slums.

Conclusions-The findings suggest that social and organisation characteristics of low income communities may have a relevant role in understanding health variations. Local health and other social programmes specifically targeting these communities are recommended.

(F Epidemiol Community Health 2000;54:530-536)
\end{abstract}

Dr Szwarcwald

(celia@malaria.procc.

fiocruz.br)

Accepted for publication 19 December 1999

Throughout the history of epidemiology, different attributes of people and their environ- ments have been considered as potential causes of disease. Socioeconomic status is one of the most consistently correlated factors of health conditions. $^{1}$

The association between socioeconomic status and morbidity and mortality is found in all countries where the relation between these factors has been examined, for most diseases and for different measures of socioeconomic status. It has been consistently noted that people of lower socioeconomic groups have poorer health than those at the top..$^{2-4}$

Recently, ecological studies have suggested that income inequality is also correlated with health status. ${ }^{5-8}$ These studies have related different indices of income inequality to several health indicators such as infant mortality, life expectancy, general cause and cause specific mortality, with a consistent finding that the more concentrated the wealth, the worse the population health status.

In addition, growing evidence suggests that the urbanisation and the rising income inequality in many countries have been accompanied by a geographical concentration of affluence and poverty in the largest cities, creating fundamental changes in the spatial patterns of health conditions. ${ }^{910}$ Economic stratification by place of residence has produced the geographical concentration of cumulative forms of disadvantages, intensifying the exposure of lower income residents to violence and diseases. ${ }^{11}$

Thus, establishing the spatiotemporal relations between health outcomes and socioeconomic variables, and relating these associations to the broader economic context and resultant changes in the social environment are essential elements for a comprehensive appreciation of the population health differentials. ${ }^{12}$

Recent advancements in computer technologies, such as geographical information systems (GIS), have provided a modern approach for integrating health outcomes to environmental, socioeconomic and demographic variables. ${ }^{13-15}$

This study examines the geographical pattern of some health indicators in the city of Rio de Janeiro, Brazil. A GIS is used to merge spatial datasets from different sources and to link health outcomes to demographic and socioeconomic indicators, including measures of income inequality and density of slum residents. The paper shows that the application of a GIS can lead to an improved interpretation of some aspects of health inequalities.

\section{Methods}

As of 1991, the municipality ${ }^{\star}$ of Rio de Janeiro, Brazil had an approximate population of 
5 million and was divided into 24 city districts that are legally denominated as "Administrative Regions" (ARs), and numerated from 1 to 24 . $^{\star}$

In 1993, a GIS was created at the Department of Information on Health (DIS/ FIOCRUZ) in consortium with the Brazilian Institute of Geography and Statistics (FIBGE), which provided the textual description of all 1991 census tract limits of the municipality of Rio de Janeiro, transcribed to a 1:5000 scale map. Approximately 6400 census tract polygons were digitised, and edited in a CAD-type software.

The GIS links all of the 1991 census demographic, economic and social datasets at the level of census tract, and enables the automated integration of census data for all health legal databases in the municipality of Rio de Janeiro. Information on location of public schools and health facilities, main roads, slums, water supply system and sewage network are also provided by the GIS.

In this investigation, information on population, income, and level of instruction received by heads of household were obtained from the GIS as well as information on location and number of slum residents for each census tract.

Mortality data were obtained from the Mortality Information System compiled by the Brazilian Ministry of Health. ${ }^{16}$ All reported deaths in the municipality of Rio de Janeiro, from 1987 to 1995 , were considered in the study. ARs are the smallest spatial units for which the Health Ministry tabulates death information.

Mortality data and population census data were merged and made compatible through the GIS. The 24 ARs that compose the city were used as the geographical units in this analysis. The AR polygons were obtained through the aggregation of the corresponding census tracts and stored in a specific layer.

For each AR, the following indicators were derived from the GIS:

(1) "illiteracy rate"-calculated as the proportion of illiterate household heads;

(2) "poverty index"-defined as the proportion of household heads who earned less than one "minimum wage" per month; $\dagger$

(3) "average income"-calculated as the average of the household head incomes;

(4) "density of slum residents"-calculated as the number of slum residents per $\mathrm{km}^{2} ; \ddagger$

(5) "proportion of slum residents"calculated as the number of slum residents divided by total population;

(6) "Gini coefficient" - a well known indicator of income inequality derived from the Lorenz curve, calculated as the area delimited by the Lorenz curve and the $45^{\circ} \operatorname{line}^{17}$;

* In Brazil, municipality is the territory of a city, including the urban and rural areas. In the case of Rio de Janeiro, an exclusively urban locality, the terms are equivalent.

† In Brazil, the minimum wage per month is established and updated annually by the Federal Government to express changes in the price of basic food and services.

t Slum ("favela") is classified by the Brazilian Institute of Geography and Statistics (FIBGE) under the heading of "informal community".
(7) "top $10 \%$ to bottom $40 \%$ average income ratio"-measures the income disparity, and is calculated by taking the average income earned by the top $10 \%$ of household heads and dividing by the average income earned by the bottom $40 \%$ of the household heads;

(8) "homicide rate"-calculated as the homicide rate among men aged 15-29 years;

(9) "infant mortality rate" - calculated as the number of infant deaths per 1000 live births;

(10) "life expectancy at birth"-obtained for each sex through the construction of a life table based on the age specific central death rates;

(11) "standardised mortality rate"calculated as the age standardised mortality rate by the direct method, taking the municipality of Rio de Janeiro age distribution as the standard distribution.

All socioeconomic variables (1-7) and population refer to 1991, as they were derived from the 1991 Brazilian census. For the sake of the analysis, the health indicators (8-11) were calculated by taking the average number of deaths in the period 1990-1992.

A principal component analysis was used to combine information on socioeconomic conditions followed by a varimax rotation of the factor loading solution to some more interpretable orientation. ${ }^{18}$ The new dimensions were used as a basis for assessing contextual variation and to aggregate the administrative regions into three different clusters. The clusters were selected to reflect the two key dimensions that were identified as significant for socioeconomic variation, delimiting three geographical sectors in the city.

Thematic maps were used to establish the geographical patterns of the health indicators through MapInfo software. ${ }^{19}$ In all maps, the administrative region values were represented by gray tones, using the 33.3 and 66.7 centiles as the class cut points.

\section{Results}

Through the principal component analysis, the original seven socioeconomic variables were reduced to two new factors. The two factors accounted for $90 \%$ of the original variability in the data. Table 1 shows the description of the new components in terms of the original variable loads. The variables that most influenced the definition of factor 1 were all related to socioeconomic standards (income, education and income distribution), while factor 2 was basically defined by the "density of slum residents".

Table 1 Varimax rotated component matrix

\begin{tabular}{lrr}
\hline & \multicolumn{2}{l}{ Component } \\
\cline { 2 - 3 } Variable & \multicolumn{2}{l}{2} \\
\hline Gini coefficient & 0.974 & 0.155 \\
Top 10\%-bottom 40\% income ratio & 0.956 & 0.195 \\
Illiteracy rate & 0.735 & 0.492 \\
Proportion of slum residents & 0.194 & 0.950 \\
Poverty index & 0.932 & 0.264 \\
Average income & -0.919 & -0.039 \\
Density of residential poverty & 0.128 & 0.932 \\
\hline
\end{tabular}




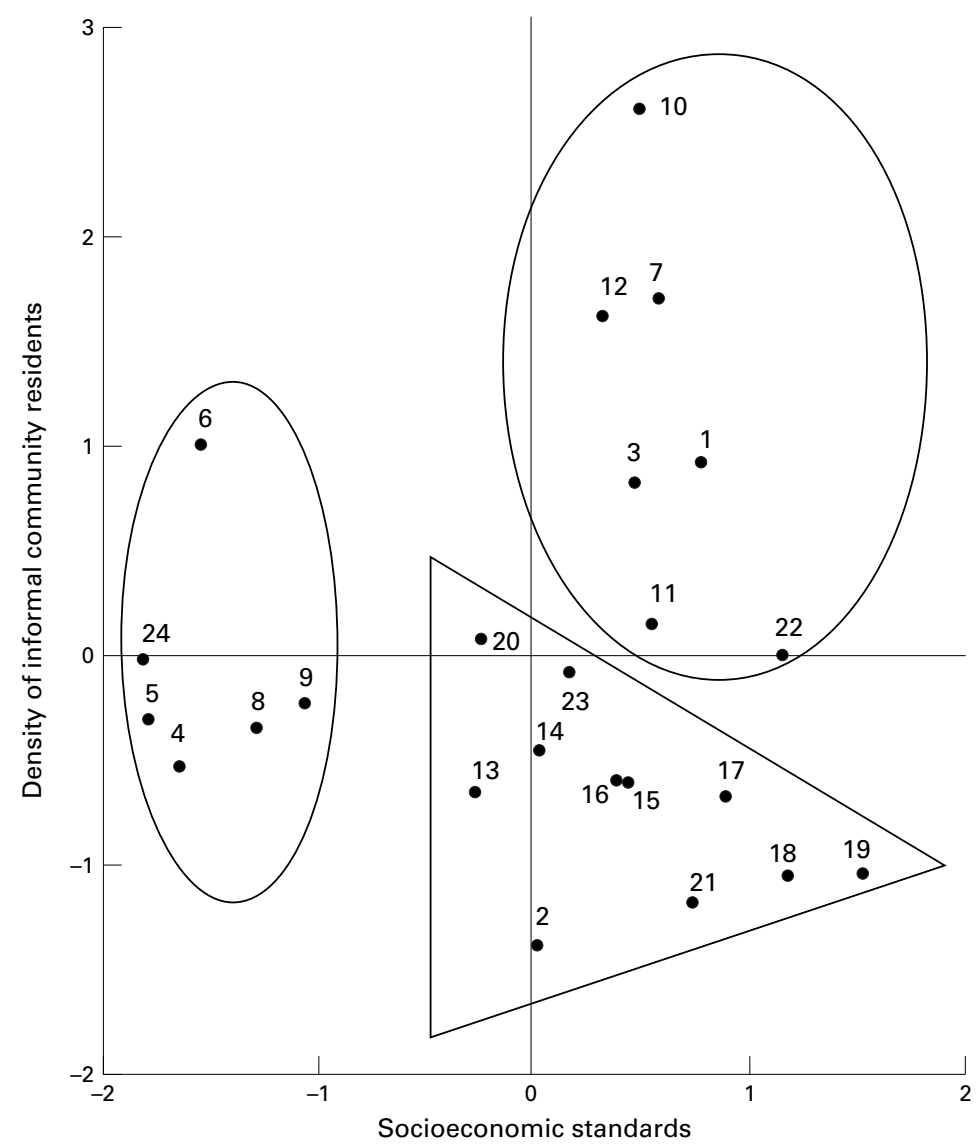

Figure 1 Administrative Region Factor Scores. Municipality of Rio de Faneiro, 1991.

The factor scores provided summary indices of the AR socioeconomic conditions by which to derive clusters of ARs. Three clusters were chosen as a natural grouping on the basis of the two new dimensions that accounted for almost all socioeconomic variation. Figure 1 shows the three selected clusters where each AR is represented by its corresponding number.

Figure 2 shows the map of the municipality of Rio de Janeiro. The three selected clusters that reflect the socioeconomic variation of the AR data were represented by different gray tones. It is worth noting that the socioeconomic structure determined a clear geographical division in the city. The light gray area represents the wealthiest sector of the city. The districts that compose this cluster are located along the coast or nearby, so it was denominated as "Coastal Sector". The dark gray cluster represents the worst sector of the city in terms of living conditions. It evidenced not only low socioeconomic standards (as measured by factor 1), but also the highest concentration of slum residents. This sector is composed of the harbour $\mathrm{AR}$ and six other ARs in the northern vicinity and was denominated "Harbour Sector". The medium gray cluster borders other municipalities located in the "Metropolitan Belt" of the State of Rio de Janeiro. As it is situated in the west, this area was denominated as the "West Sector". This cluster also concentrated low income population but did not show a high density of slum residents. The concentration of slum residents in the dark gray sector of the city can be better visualised by the two different layers of the map (selected clusters and locations of slums).

From the health indicator thematic maps, it can be observed that the geographical patterns of health inequality followed the same spatial pattern determined by the socioeconomic structure of the AR-based data. A cluster of unfavourable health conditions could be identified in the maps corresponding to the homicide rate, the standardised mortality rate and life expectancy at birth. As an example, the thematic map for the homicide rate is displayed in figure 3. The worst health situation was

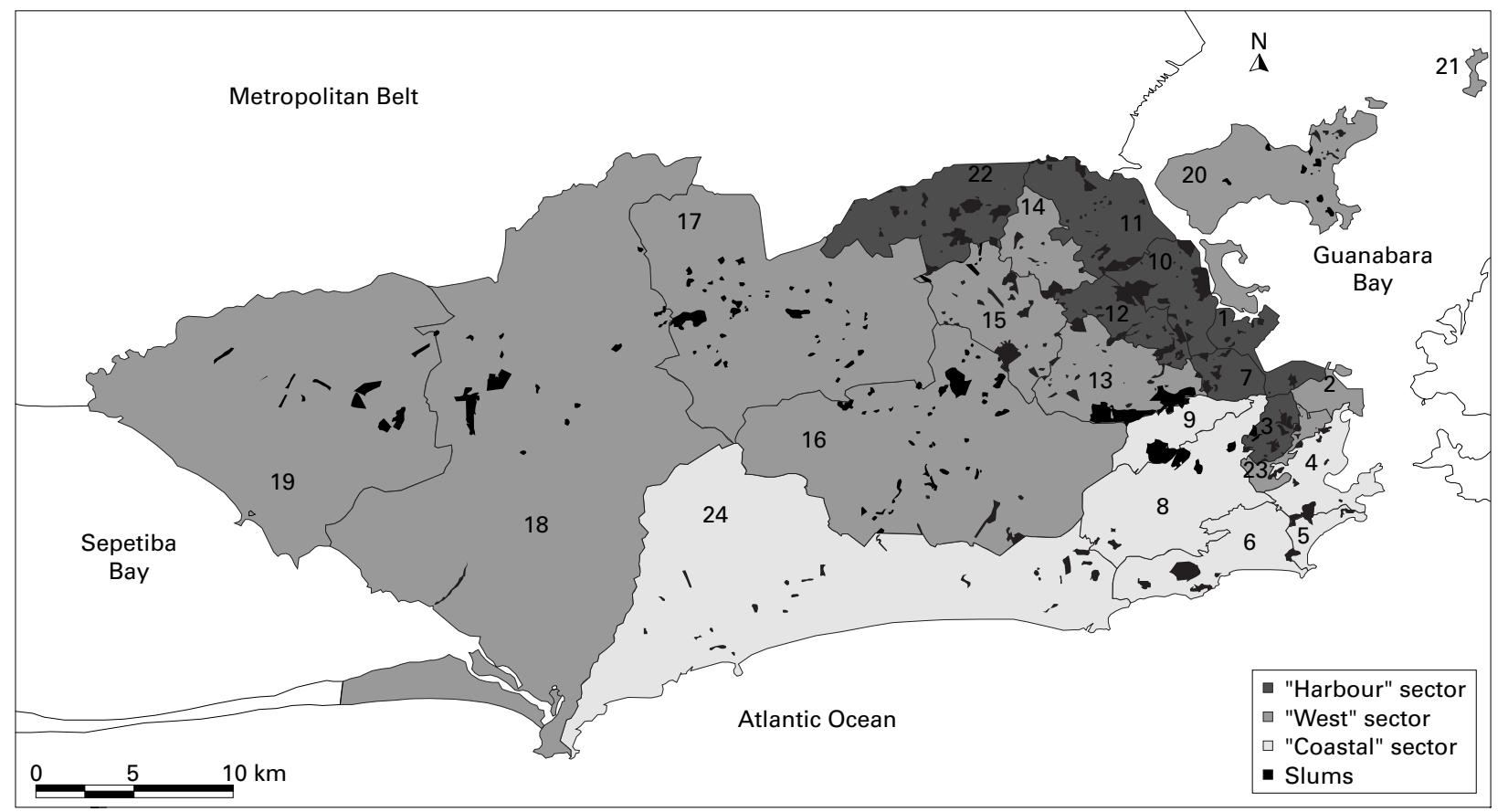

Figure 2 Selected clusters and locations of slums. Municipality of Rio de faneiro, 1991. 


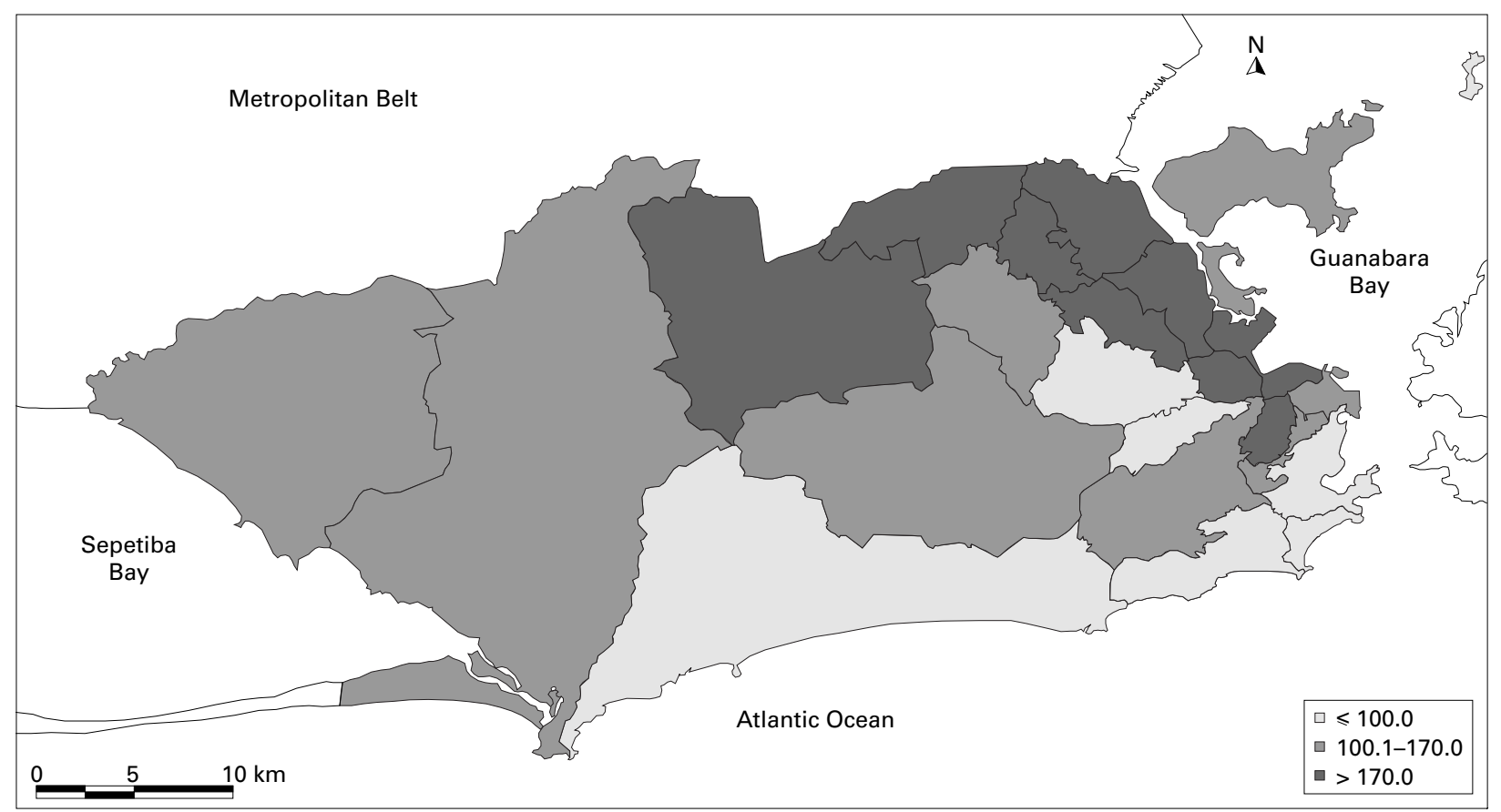

Figure 3 Geographical distribution of the homicide rate (per 100000 population) among men aged 15-29 years. Municipality of Rio de faneiro, 1991.

established precisely in the sector that concentrates very poor living standards and the highest density of slum residents (Harbour Sector).

The infant mortality rate showed a somewhat different spatial pattern. Although the lowest values were concentrated in the wealthiest sector of the city, an apparently random distribution of high values was found among the ARs located in the West and Harbour sectors (fig 4). The inadequacy of the newborn assistance care can be visualised by the second layer of the map, which represents the AR number of neonatal intensive care beds.
Descriptive statistics of all variables used in this study in each of the three clusters are summarised in table 2. Although the quantitative description confirms the geographical characterisation, some results should be highlighted. The Harbour Sector showed: the most unbalanced income distribution with an average income of the top $10 \%$ household heads 29 times higher than the bottom $40 \%$; the worst health situation as measured by all health indicators; an extremely high value of the homicide rate, greater than 200 per 100000 population; a nine year difference in the life

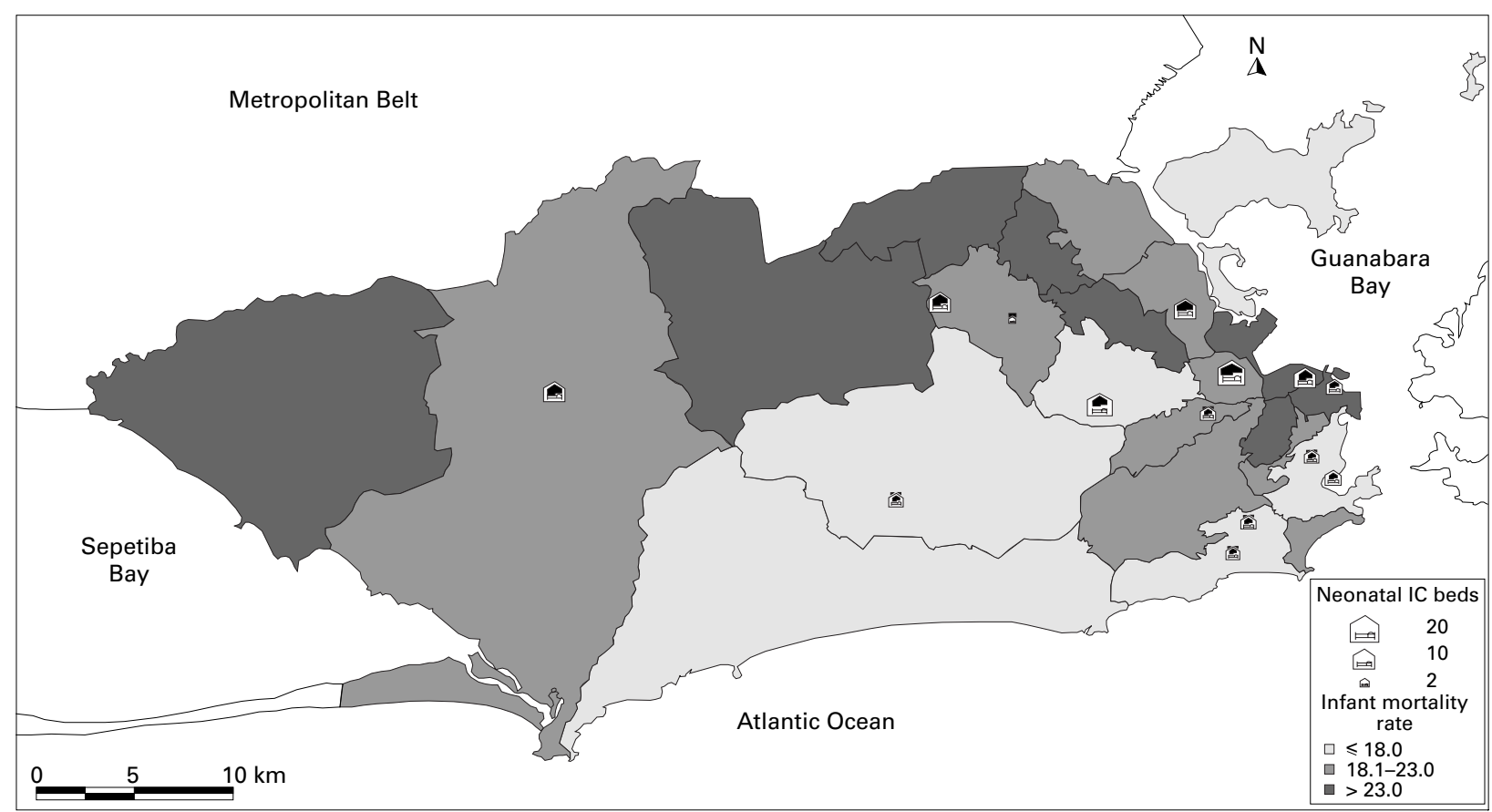

Figure 4 Geographical distribution of the infant mortality rate (per 1000 live births) and number of neonatal intensive care beds. Municipality of Rio de faneiro, 1991. 
Table 2 Socioeconomic and health indicators by sector of the Municipality of Rio de faneiro, 1991

\begin{tabular}{|c|c|c|c|c|}
\hline \multirow[b]{2}{*}{ Indicator } & \multicolumn{4}{|l|}{ Sector } \\
\hline & Harbour & West & Coastal & Total \\
\hline Gini coefficient & 0.61 & 0.58 & 0.45 & 0.56 \\
\hline Top $10 \%$-bottom $40 \%$ income ratio & 28.57 & 24.72 & 12.50 & 22.79 \\
\hline Poverty index & 22.70 & 18.74 & 6.21 & 16.47 \\
\hline Illiteracy rate & 10.17 & 7.53 & 4.10 & 7.51 \\
\hline Average income & 3.10 & 4.08 & 12.50 & 6.13 \\
\hline Proportion of slum residents & 30.69 & 11.04 & 12.40 & 17.55 \\
\hline Density of residential poverty & 37.74 & 4.64 & 8.02 & 17.82 \\
\hline Life expectancy at birth & 64.01 & 68.36 & 73.25 & 67.99 \\
\hline Homicide rate & 211.17 & 132.70 & 72.08 & 148.58 \\
\hline Standardised mortality rate & 11.23 & 8.31 & 6.39 & 8.68 \\
\hline Infant mortality rate & 26.00 & 20.21 & 17.52 & 21.23 \\
\hline Male AIDS mortality rate & 65.73 & 45.34 & 75.14 & 56.25 \\
\hline Female AIDS mortality rate & 10.04 & 7.07 & 7.88 & 7.86 \\
\hline
\end{tabular}

expectancy at birth compared with the wealthiest sector.

\section{Discussion}

In the past few decades, Brazil has experienced a significant increase in income inequality. Actually, according to the World Bank Report, ${ }^{20}$ Brazil has one of the most unbalanced income distributions of the world.

Urbanisation along with rural migration and the rising income inequality have produced a geographical concentration of poverty, particularly in the metropolitan areas of the country. Specifically in São Paulo and Rio de Janeiro, the two main cities of Brazil, the number of slums has grown sharply over the past 20 years.

The geographical analysis presented in this paper identified a socioeconomic stratification of the city of Rio de Janeiro by place of residence. The socioeconomic structure, basically oriented by socioeconomic standards and concentration of low income communities, determined a clear geographical division in the city.

With respect to the geographical and socioeconomic stratification, some aspects should be considered particularly. Firstly, it is important to note that the principal component analysis distinguished "slum residence" from "socioeconomic status", generating two independent factors despite the fact that slums are also composed of low income residents. Secondly, the worst health situation was found precisely in the sector with the greatest concentration of slums. Therefore, this study evidenced not only a pronounced class geographical segregation but also that the health differentials followed exactly the same segregation pattern.

Growing literature in recent years suggests that features of the environments in which people live may exert an important influence on health deterioration or health promotion. ${ }^{71-23}$ It is currently believed that the spatial health contrasts may not be simply attributable to the within area concentration of people with adverse socioeconomic conditions. That is, the residential environment cannot be simply considered as a compositional effect but rather as a contextual effect. ${ }^{24}$

The evidence of relevant health differences in a specific sector of the city of Rio de Janeiro supports the hypothesis that properties of the
KEY POINTS

- The geographical analysis clearly identified a socioeconomic stratification of the city of Rio de Janeiro by place of residence.

- The findings suggest that social and organisation characteristics of low income communities may have a relevant role in understanding health variations.

- The results advocate in favour of local programmes for health promotion, which considers community features in addition to individual features.

- The effective urbanisation of the slums and their integration with the society at large are necessary.

- The creation of urban ghettos can only contribute towards the intensification of mutual social mistrust, poor health conditions and violence.

environment of residence may be contextually influencing health. We specifically note that the "Harbour" and "West" sectors are both composed of low income residents but have great variations in health indicators.

The deterioration of health conditions in the sector of Rio de Janeiro that aggregates the highest proportion of slum residents suggests that people living in situations characterised by social disorganisation and poverty are at increased risk. These situations have been described in terms of rupture of social cohesion and absence of resources available to people living in such environments. ${ }^{71025}$ It is believed that social cohesion deteriorates within neighbourhoods according to their degree of relative deprivation in relation to the wider society. ${ }^{26}$ Relative deprivation results in frustration, stress, family and social disruption, which in turn increase violence, crime rates, drug misuse, alcoholism and other social outcomes likely to adversely affect health. ${ }^{10}$

There is a considerable literature linking social integration to health outcomes. ${ }^{25-28} \mathrm{Re}-$ sults have demonstrated that social and community ties may benefit the socialisation of urban low income community residents, bringing them in as participating members of the larger society. ${ }^{28}$ Sampson $e t a l^{11}$ have shown that the association between concentration disadvantage and violent crime may be mediated by the level of collective efficacy, measured by the resident willingness to intervene on common goods.

The growing number of homicides in the informal communities of the city of Rio de Janeiro is known to be linked to organised criminal activities related to the drug traffic. It is believed that low income youth are easily seduced by the immediate offers of money and leadership positions as a consequence of the increased levels of frustration brought about the deprivation of social goods and lack of opportunities of personal growth. Involved in the dispute of drug trafficking control points, they end up killing each other and dying very young. ${ }^{29}$ 
Regarding the infant mortality rate, a specific pattern was found, different from the other health indicators under analysis. The variations in the infant mortality geographical distribution are probably attributable to the different behaviours of its components, the neonatal (under 28 days) and postneonatal mortality (28 days to 1 year). Actually, the main component of the infant mortality in Rio de Janeiro is the neonatal mortality, which is related to broad socioeconomic conditions, but particularly to the access to health care facilities and to the quality of perinatal care. ${ }^{30}$

Some limitations of the present investigation should be pointed out. Although the completeness of death registration in the State of Rio de Janeiro is known to be approximately $97 \%{ }^{31}$ the study is based on secondary data, which may have problems of enumeration and classification. For instance, homicide rates are believed to be higher than the presented ones as homicide deaths for which intention cannot be proved are classified as "firearm injuries ignored if intentionally caused" (ICD E985). Even knowing that these misclassifications could affect the results, a proper assumption is that they occur mostly in the poorest areas. In this sense, eventual corrections of the data would probably intensify even more the contrasts depicted here.

Another limitation refers to the geographical unit of analysis - that is, the AR, which is known to be quite heterogeneous. None the less, it is the smallest area for which mortality data are available. Furthermore, the study must be complemented by longitudinal analyses, investigating the geographical expansion of low income communities in the late years, along with the time trend of the health indicators.

\section{Conclusions}

GIS is a powerful tool to assess multilevel phenomena because of their capacity to use different levels of data aggregation depicted as distinct graphic layers. As indicated by the WHO's Healthy Cities project and network, ${ }^{32}$ the integration of social and health information from different sources, especially when it includes the analysis of small areas indicators, constitutes a core strategy to provide sound data for health analysts and planners.

In this investigation, by explicitly linking health outcomes to sociophysical variables, the GIS allowed us to reorient our explanations for health differentials that the traditional statistical methods would not be capable of capturing. The geoepidemiological analysis provided evidence that advocates in favour of local programmes of health promotion, which consider features of the communities in addition to individual features.

Although the available slum programmes are clearly limited, as most of them are deficiently funded and staffed, some successful initiatives must be mentioned. Created in the beginning of 1994, the "Favela-Bairro Program" is a City Hall programme that aims to change the medium size "favelas" into low income districts with basic infrastructure services such as pluvial water drainage, lighting and public rubbish collection. ${ }^{33}$

However, the main problem of the "favelas" is the appropriation of these low income areas by drug traffic organisations. For the slum young residents, drug trafficking means a job and the only way of meeting some of their needs. Lack of formal employment opportunities for an unprepared youth certainly contributes to increase involvement of young slum residents in this activity. ${ }^{34}$

Professional education, health and other social programmes specifically targeting these youth, including programmes to reduce the harmful effects of relative deprivation and efforts to strengthen social ties, may have an important impact on underprivileged youth survival. A well established programme in the "Favela da Mangueira" engages children and teenagers in athletic activities, which promotes socialisation through education and entertainment.

The government, in its different levels and competence, the private companies, the community leaderships, and the society, in general, have their share in the pressing need of improvement of this unbearable social context. In this sense, strategies of shared management could enlarge the possibilities of execution of effective and enduring actions, mainly in regard to projects turned to social development and integration of the slums into the city and the society at large. The creation of urban ghettos can only contribute towards the intensification of mutual social mistrust, poor health conditions and violence.

Funding: this research was funded by an Oswaldo Cruz Foundation grant (PAPES no 0250.250.369), and the National Research Council (CNPq; salary grants for CLS, FIB and CB). Conflicts of interests: none.

1 Duncan GJ. Income dynamics and health. Int $\mathcal{f}$ Health Serv 1996;26:419-44.

2 Marmot MG, Kogeniva M, Elston MA. Social-economic status and health. Annu Rev Public Health 1987;8:111-35.

3 Towsend P, Davidson N, eds. Inequalities in health. The Black Report and The Health Divide. London: Penguin, 1990.

4 Adler N, Boyce WT, Chesney MA, et al. Socioeconomic difAdler N, Boyce WT, Chesney MA, et al. Socioeconomic dif-
ferences in health: no easy solution. $7 A M A$ 1993;269: ferences

5 Wilkinson RG. Nation mortality rates: The impact of inequality? Am f Public Health 1992;82:1082-4.

6 Wilkinson RG. Income distribution and life expectancy. BMF 1992;304:165-8.

7 Kaplan GA, Pamuck ER, Lynch JW, et al. Inequality in income and mortality in the United States: Analysis of mortality and potential pathways. BMF 1996;312:9991003.

8 Kennedy BP, Kawachi I, Prothrow-Stith D. Income distribution and mortality: cross sectional ecological study of the Robin Hood index in the United States. BM $\mathcal{F} 1996$; 312:1004-7.

9 Massey DS. The age of extremes: concentrated affluence and poverty in the twenty-first century. Demography 1996; 33:395-412.

10 Kawachi I, Kennedy BP. Health and social cohesion: why care about income inequality? BMF 1997;314:1037-40.

11 Sampson RJ, Raudenbush SW, Earls F. Neighborhoods and violent crime: A multilevel study of collective efficacy. Science 1997;277:918-24.

12 Kaplan GA. People and places: contrasting perspectives on the association between social class and health. Int 7 Health Serv 1996;26:507-19.

13 Tim US. The application of GIS in environmental health sciences: opportunities and limitations. Environ Res 1995; 71:75-88.

14 Croner CM. Geographic Information Systems (GIS): New perspectives in understanding human health and environmental relationships. Stat Med 1996;15:1961-77.

15 Vine MF, Degnan D, Hanchette C. Geographic Information Systems: Their use in environmental epidemiologic research. Environ Health Perspect 1997;105:598-605. 
16 Brasil, Ministério da Saúde. Sub-sistema de Informacões sobre mortalidade, Brasil, 1979-1993. Brasília: Data/SUS (CD mortalidade,

17 Hammond R, McCullagh PS. Quantitative techniques in geography: an introduction. Oxford: Clarendon Press, 1978. 18 Green PE. Analyzing multivariate data. Hinsdale, Illinois: The Dryden Press, 1978.

19 MapInfo. Reference. Troy, New York: MapInfo Corporation, 1994.

20 World Bank. World Bank Development Report 1995. New York: Oxford University Press, 1995.

21 Macintyre S, Maciver S, Sooman A. Area, class and health: should we be focusing on places or people? fournal of Social Policy 1993;22:213-34.

22 Humpreys K, Car-Hill R. Area variations in health outcomes: Artifact or ecology. Int f Epidemiol 1991;20:251-

$$
8 \text {. }
$$

23 Haan M, Kaplan GA, Camacho T. Poverty and health. Prospective evidence from the Alameda county study. Am $\mathcal{F}$
Epidemiol $1987 ; 125: 989-98$.

24 Shouls S, Congdon P, Curtis S. Modeling inequality in reported long term illness in the UK: combining individual and area characteristics. I Epidemiol Community Health 1996;50:366-76.

25 Berkman LF, Syme SL. Social networks, host resistance and mortality: a nine-year follow-up study of Alameda county residents. Am $\mathcal{F}$ Epidemiol 1979;109:186-204.
26 Wilkinson RG. Comment: Income, inequality, and social cohesion. Am f Public Health 1997;87:1504-6.

27 Kawachi I, Kennedy BP, Lochner K, et al. Social capital, income inequality, and mortality. Am F Public Health 1997; 87:1491-8.

28 House JS, Landis KR, Umberson D. Social relationships and health. Science 1988;214:540-5.

29 Minayo MCS. Inequality, violence and ecology in Brazil. Cad Saude Publica 1994;10:241-50.

30 Leal MC, Szwarcwald CL. Characteristics of neonatal mortality in the State of Rio de Janeiro, Brazil, in the 1980s: a spatio-temporal analysis [Portuguese]. Rev Saude Publica spatio-temporal

31 Szwarcwald CL, Castilho EA. Estimates of infant mortality in the 80s: A proposal for a methodological procedure [Portuguese]. Rev Saude Publica 1995;29:451-62.

32 Webster P. Review of the "City Health Profiles" produced by WHO-Healthy Cities-do they present information on health and its determinants and what are their perceived benefits? F Epidemiol Community Health 1999; 53:125-127

33 Municipal Secretariat of Housing. The "Whole City": The Housing Policy of Rio de faneiro City [Portuguese]. Rio de Housing Policy of Rio de faneiro City [Portuguese]

34 Souza MJL. Crime, violence, and urban (under) development: Drug traffic and its socio-spatial impacts in Rio de Janeiro, Brazil. Eur Geogr 1995; 9:105-111. 